\title{
The Fusobacterium nucleatum porin FomA possesses the general topology of the non-specific porins
}

\author{
Pål Puntervoll, ${ }^{1}$ Hans Kleivdal, ${ }^{1}$ Karl Ole Dahl, ${ }^{1}$ Wilbert Bitter, ${ }^{2}$ \\ Jan Tommassen ${ }^{2}$ and Harald B. Jensen ${ }^{1}$
}

Author for correspondence: Pål Puntervoll. Tel: +47 55584500. Fax: +4755589683.

e-mail: pal.puntervoll@mbi.uib.no

\footnotetext{
1 Department of Molecular Biology, University of Bergen, HiB, Thormøhlensgate 55 , N-5020 Bergen, Norway

2 Department of Molecular Microbiology and Institute of Biomembranes, Utrecht University, Padualaan 8, $3584 \mathrm{CH}$ Utrecht, The Netherlands
}

\begin{abstract}
FomA is a major non-specific porin of Fusobacterium nucleatum with no sequence similarity to other known porins. According to the topology model, the protein consists of 16 transmembrane $\beta$-strands, connected by eight surface-exposed loops and seven periplasmic turns. In this study, the insertion mutagenesis approach was applied to probe the topology model. A Semliki Forest Virus (SFV) epitope was successfully inserted at 11 different sites of the FomA protein and a 6-aa insertion was successfully inserted at two different sites. Correct folding of the mutant proteins and proper incorporation into the outer membrane were assessed by heat modifiability and by an in vivo porin activity assay. Immunofluorescence microscopy analysis of intact cells, using mAbs directed against the inserted SFV epitope, revealed that three of the eight putative extracellular loops are indeed surface-exposed. Trypsin accessibility experiments confirmed the cell surface exposure of two additional loops. The results support the proposed topology model, showing that FomA possesses the general $\beta$-barrel topology of the non-specific porins, with the interesting exception that the third loop does not seem to fulfil the role of a constriction loop.
\end{abstract}

Keywords: outer-membrane proteins, porins, Fusobacterium nucleatum, topology, epitope insertion mutagenesis

\section{INTRODUCTION}

The outer membrane of Gram-negative bacteria serves as a firm barrier, protecting the cell from environmental stress. However, this barrier must be penetrable for nutrients, such as sugars, nucleosides and amino acids. The major route of uptake for these hydrophilic molecules is constituted by the pore-forming proteins termed porins (Nakae, 1976; Welte et al., 1995). Threedimensional structures of several porins have been resolved in the last few years and have revealed that the porins are organized as trimers. Each monomer contains 16 amphipathic, antiparallel membrane-spanning $\beta$ strands, which create a $\beta$-barrel with a hydrophilic interior (Cowan, 1993; Montal, 1996; Weiss et al., 1991).

Fusobacterium nucleatum is an anaerobic, Gram-nega-

Abbreviations: wtFomA, wild-type FomA; mFomA, mutant FomA; OMP, outer-membrane protein; SFV, Semliki Forest Virus. tive bacterium and one of the predominant species among the periodontal bacteria (Bolstad et al., 1996). It plays a major role in the colonization of the teeth by acting as a bridge between early and late colonizers of the tooth surface (Kolenbrander \& London, 1993). The fusobacterial major outer-membrane protein (OMP), FomA, has been suggested to participate in this coaggregation process by directly binding to Streptococcus sanguis (Kaufman \& DiRienzo, 1989). It has been shown that FomA forms trimeric, water-filled channels in lipid bilayer membranes, acting as non-specific pores (Kleivdal et al., 1995). The deduced amino acid sequences of the FomA proteins from several strains (Bolstad et al., 1995, 1994) revealed no sequence similarity to other known porins. However, a topology model was proposed on the basis of an alignment between the FomA sequences from three F. nucleatum strains and of the structural principles derived from OMPs of Escherichia coli (Bolstad et al., 1994). The fom A gene of F. nucleatum ATCC 10953 has been successfully cloned and expressed in E. coli (Jensen et 
al., 1996) and this has rendered possible the use of mutagenesis as a strategy for probing the proposed topology model.

Epitope insertion mutagenesis has proved to be a valuable experimental approach to obtain structural information on OMPs in the absence of a crystal structure. Since the approach was introduced in the study of LamB (Charbit et al., 1986), it has been successfully applied to several bacterial OMPs (Agterberg et al., 1987; Merck et al., 1997; Moeck et al., 1994; Sukhan \& Hancock, 1995; Taylor et al., 1990). In a recent study on the topology of LamB, results obtained with the epitope insertion method coincided well with the X-ray model (Newton et al., 1996). In the present study, this approach was applied to the FomA protein.

\section{METHODS}

Bacterial strains and growth conditions. E. coli strain DH $5 \alpha$ (Hanahan, 1983) was used for cloning purposes. Wild-type FomA (wtFomA) and all mutant FomA proteins (mFomAs) were expressed in the porin-deficient E. coli K-12 strain CE1224 (Tommassen et al., 1983). E. coli was grown aerobically at $37^{\circ} \mathrm{C}$ with vigorous shaking in LB medium, or, to impose phosphate limitation, in a medium described by Levinthal et al. (1962). When necessary, appropriate antibiotics were added for selective purposes at the following concentrations $\left(\mu \mathrm{g} \mathrm{ml}^{-1}\right)$ : chloramphenicol, 35; ampicillin, 50 ; tetracycline, 50 .

Mutagenesis. Plasmid pHB14 (Jensen et al., 1996) is a pACYC184 derivative and contains the part of the fom $A$ gene encoding the mature part of the FomA protein, immediately downstream of the phoE promoter and signal sequenceencoding part of $p h o E$. The pHB14 plasmid was the parent to all constructs made in this study.
Novel BamHI sites were introduced after the codons for aa 19 and 287 by PCR (Ho et al., 1989), resulting in plasmids pSB19 and pSB287, and after the codons for aa 105, 143 and 191 by the double-primer method (Ohmori, 1994), resulting in plasmids pHK105, pHK143 and pHK191.

For BamHI-linker insertion mutagenesis, pHB14 was randomly linearized by digesting with the frequently cutting restriction endonuclease $\mathrm{Mse} \mathrm{I}$ in the presence of ethidium

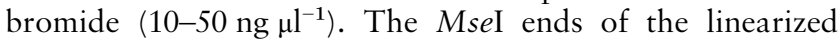
plasmid were made blunt by using the Klenow fragment of $E$. coli DNA polymerase I. Linear blunt-ended pHB14 (10-100 $\mathrm{ng})$ was ligated to $1 \mu \mathrm{g}$ of a dephosphorylated self-annealing 12-mer BamHI oligonucleotide (5'-CGCGGATCCGCG-3'). The great excess of BamHI linker resulted in linear pHB14 with one $\mathrm{Bam} \mathrm{HI}$ oligonucleotide ligated to each end. The ligation mixture was subjected to agarose gel electrophoresis to remove excess BamHI linker, the band corresponding to the linear plasmid was excised from the gel and the DNA was extracted with the JETSORB kit (Genomed). The isolated DNA was heated to $65^{\circ} \mathrm{C}$ to remove the non-covalently bound linker strands, followed by slow cooling to room temperature, resulting in circularization of the plasmids due to annealing of the complementary $B a m \mathrm{HI}$ oligonucleotide strands. The circularized plasmids were used to transform $E$. coli strain DH5 $\alpha$. Transformants were screened by restriction enzyme analysis. Novel BamHI sites were introduced by linker insertions in MseI sites after the codons for aa 97, 116, 130, $138,167,211,215,236,245$ and 333, resulting in plasmids designated $\mathrm{pMB}$ followed by the respective codon numbers.

The constructs containing unique BamHI sites were used to insert a double-stranded oligonucleotide encoding a Semliki Forest Virus (SFV) B-cell epitope (Merck et al., 1997; Snijders et al., 1991), consisting of aa 240-255 of the E2 protein of SFV (Table 1). This was achieved by linearizing the various plasmids with the restriction endonuclease BamHI, followed by ligating $1 \mu \mathrm{g}$ of the SFV linker to $10-100 \mathrm{ng}$ linearized

Table 1. Nucleotide sequences of oligonucleotides encoding the SFV B-cell epitope, with amino acid translations

\begin{tabular}{|c|c|}
\hline Linker & Nucleotide and amino acid sequence \\
\hline $\mathrm{C}$ & 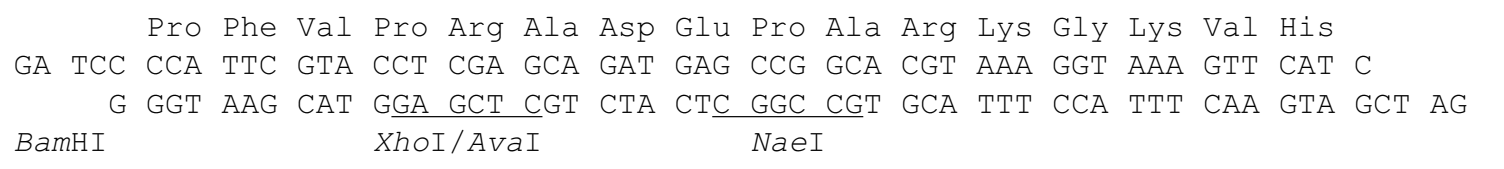 \\
\hline $\mathrm{D}$ & $\begin{array}{lcccccccccc} & \text { Pro Phe Val Pro Arg Ala Asp Glu Pro Ala Arg Lys Gly Lys Val His } \\
\text { GAT CCT CCA TTC GTA CCT CGA GCA GAT GAG CCG GCA CGT AAA GGT AAA GTT CAT } & \\
\text { GA GGT AAG CAT GGA GCT CGT CTA CTC GGC CGT GCA TTT CCA TTT CAA GTA C TAG } \\
\text { BamHI }\end{array}$ \\
\hline $\mathrm{E}$ & 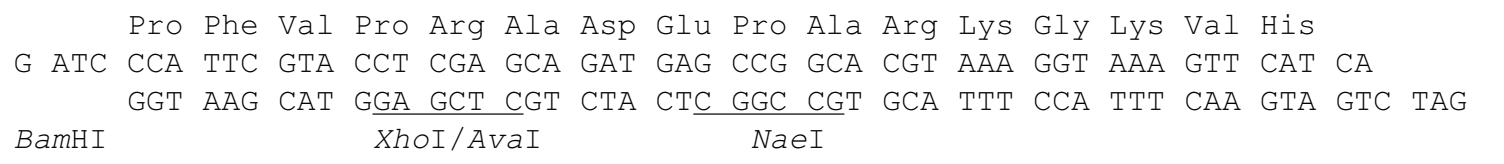 \\
\hline $\mathrm{C}^{\prime}$ & $\begin{array}{ccccccccccc}\text { Pro Phe Val Pro Arg Ala Asp Glu Pro Ala Arg Lys Gly Lys Val His } \\
\text { GA TCC CCA TTC GTA CCT CGA GCA GAT GAG CCG GCA CGT AAA GGT AAA GTT CAT CA } \\
\text { G GGT AAG CAT GGA GCT CGT CTA CTC GGC CGT GCA TTT CCA TTT CAA GTA GTC TAG } \\
\text { BamHI } \\
\text { XhoI/AvaI }\end{array}$ \\
\hline$E^{\prime}$ & 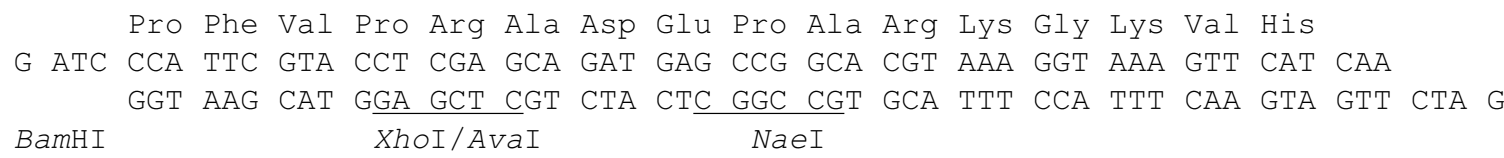 \\
\hline
\end{tabular}


Table 2. Summary of all constructs carrying insertions and the results obtained with constructs encoding mFomAs with permissible insertions

\begin{tabular}{|c|c|c|c|c|c|c|}
\hline Plasmid & $\begin{array}{c}\text { Mutant } \\
\text { protein } \\
\text { designation }\end{array}$ & $\begin{array}{l}\text { Amino acids } \\
\text { mutated or } \\
\text { inserted* }\end{array}$ & $\begin{array}{c}\text { Expression } \\
\text { of FomA }\end{array}$ & $\begin{array}{c}\text { Rate of } \\
\text { cephaloridine } \\
\text { uptake }(\%) \dagger\end{array}$ & $\begin{array}{l}\text { Mass of mFom } A \\
\text { fragments from } \\
\text { trypsin digestion } \\
\text { of intact } \\
\text { cells }(\mathrm{kDa}) \ddagger\end{array}$ & Immunofluorescence $\mathbb{S}$ \\
\hline pHB14 & wtFomA & & + & $100 \pm 17$ & - & - \\
\hline pSB19SFV & SFV-19 & 19-GS- $\underline{S F V-R S-22}$ & + & $132 \pm 32$ & - & - \\
\hline pMB97SFV & SFV-97 & 97-RGS-SFV-QIR V-98 & + & $57 \pm 12$ & $33(12,30)$ & - \\
\hline pHK105SFV & SFV-105 & 105-GS- $\overline{S F V-R S-108}$ & + & $81 \pm 32$ & $33(13,29)$ & + \\
\hline pMB116SFV & SFV-116 & 116-RGS- $\overline{S F V}$-QIR V-117 & + & $118 \pm 21$ & $33(15,28)$ & + \\
\hline pMB130SFV & SFV-130 & 130-TRI-SFV-DPR-131 & + & $66 \pm 9$ & - & - \\
\hline pMB138SFV & SFV-138 & 138-TRI-SFV-DPR-139 & + & $28 \pm 7$ & $22,28(17,26)$ & - \\
\hline pHK143SFV & SFV-143 & 143-GS-SFV-RS-146 & + & $56 \pm 13$ & - & - \\
\hline pMB167SI & & 167-TRIDPR-168 & - & & & \\
\hline pHK191SFV & SFV-191 & 191-S- $\underline{S F V-R S-193}$ & + & $107 \pm 15$ & $26,22(23,19)$ & + \\
\hline pMB211SFV & SFV-211 & 211-TRI-SFV-DPR-212 & + & - & - & - \\
\hline pMB215SI & & 215-RGSIRV-216 & - & & & \\
\hline pMB236SI & SI-236 & 236-RGSIRV-237 & + & $98 \pm 23$ & $33(27,13)$ & \\
\hline pMB236SFV & SFV-236 & 236-RGS-SFV-QIR V-237 & + & $21 \pm 13$ & - & - \\
\hline pMB245SI & SI-245 & 245-RGSIRV-246 & + & $72 \pm 42$ & $33(29,12)$ & \\
\hline pMB245SFV & & 245-RGS-SFV-QIRV-246 & - & & & \\
\hline pSB287SFV & SFV-287 & 287-GS-SFV-RS-290 & + & $103 \pm 20$ & $38(34,8)$ & + \\
\hline pMB333SI & & 333-TRIDPR-334 & - & & & \\
\hline
\end{tabular}

* Mutations are indicated by the number of the last unchanged amino acid, followed by the mutated or inserted amino acid(s) and the number of the first unchanged amino acid following the mutation. The amino acid numbering refers to that of the native FomA sequence (see legend to Fig. 1). SFV indicates the insertion of amino acids 239-PFVPRADEPARKGLVH-256 of the SFV E2 protein.

†wtFomA uptake rate was set to $100 \%$ and the values for the mFomA porins are given as percentage activity compared to the wild-type protein. The values given are means $( \pm \mathrm{SD})$ of independent assays $(n=5)$, except SFV-287 $(n=4)$. SFV-211 showed no detectable pore activity.

‡ The molecular masses of trypsin-sensitive mFomAs were estimated from Western blots. The expected sizes of the fragments are given in parentheses ( $\mathrm{N}$-terminal fragment, $\mathrm{C}$-terminal fragment). - , mFomAs that are trypsin-resistant in the same manner as wtFomA.

\Summary of data from Fig. 3.

plasmid. The ligation mixture was used to transform E. coli strain DH5 $\alpha$. Linkers encoding the SFV epitope were successfully introduced into 12 of the novel BamHI sites (Table 2). Insertion of the BamHI linker into the MseI sites (i.e. the pMB plasmids) resulted in a change of reading frame. To accommodate in-frame mutations when inserted into the $\mathrm{pMB}$ mutants, linkers $\mathrm{C}^{\prime}$ and $\mathrm{E}^{\prime}$ were used (Table 1). They are the same as $\mathrm{C}$ and $\mathrm{E}$, respectively, but contain one additional base. The plasmids carrying SFV epitope insertions were named after their respective parental plasmids followed by SFV (e.g. pMB236SFV) and the mutant proteins encoded by these plasmids were named SFV followed by the number of the last unchanged amino acid (e.g. SFV-236) (Table 2).

The reading frame change in the pMB plasmids was exploited to construct small 6 aa insertions after aa 167, 236, 245 and 333. This was achieved by opening plasmids pMB167, pMB236, pMB245 and pMB333 with BamHI, followed by blunting and ligation. The resulting plasmids were named after their respective parental plasmids followed by SI (small insertion) and the encoded mutant proteins were named SI followed by the number of the last unchanged amino acid (Table 2).

All mutations were confirmed by using the ABI PRISM BigDye
Terminator Cycle Sequencing Ready Reaction Kit and the ABI PRISM 377 DNA Sequencer (Applied Biosystems).

SDS-PAGE and Western blotting. SDS-PAGE was performed as described by Lugtenberg et al. (1975). Prior to electrophoresis, the samples were incubated for $5 \mathrm{~min}$ in sample buffer either at room temperature or at $95^{\circ} \mathrm{C}$. Proteins were visualized by staining with the fluorescent dye SYPRO Orange (Molecular Probes) and protein quantification was performed on a Fluorescent Image Analyser FLA-2000 (Fujifilm). Western blotting was performed with the Bio-Rad Mini Trans-Blot System by the procedure described by Towbin et al. (1979). The anti-FomA antiserum $\phi 239$ (Bakken et al., 1989a) and horseradish-peroxidase-coupled goat anti-rabbit antibody (Bio-Rad) were used as primary and secondary antibody respectively. Immunoblots were developed with 4-chloro-1naphtol (Bio-Rad).

Preparation of crude cell envelopes. Crude cell envelopes were prepared by pelleting cells from $10 \mathrm{ml}$ of an overnight culture and resuspending the pellet in $1 \mathrm{ml} 50 \mathrm{mM}$ Tris $/ \mathrm{HCl}$, $2 \mathrm{mM}$ EDTA (pH 8.5). The cells were disrupted by ultrasonication at $0{ }^{\circ} \mathrm{C}$. Intact cells were removed by centrifugation $(1000 \mathrm{~g}, 20 \mathrm{~min})$ and the crude cell envelopes were pelleted 
by centrifugation at $15000 \mathrm{~g}$ for $45 \mathrm{~min}$. The pellet was resuspended in $60 \mu \mathrm{l} 0 \cdot 2 \%$ Triton $\mathrm{X}-100$ in $2 \mathrm{mM}$ Tris $/ \mathrm{HCl}$ (pH 8.0).

Trypsin accessibility experiments. Cells were incubated with trypsin as described by Merck et al. (1997). Cells from an overnight culture were pelleted and resuspended in a buffer containing $0 \cdot 1 \mathrm{M}$ Tris $/ \mathrm{HCl}(\mathrm{pH} 8 \cdot 0), 0.25 \mathrm{M}$ sucrose and $10 \mathrm{mM} \mathrm{MgCl}_{2}$. The samples were incubated for $60 \mathrm{~min}$ at $37{ }^{\circ} \mathrm{C}$ with $0 \cdot 1 \mathrm{mg}$ trypsin $\mathrm{ml}^{-1}$. The treated cells were washed twice in $1 \mathrm{ml}$ digestion buffer, containing $500 \mu \mathrm{g}$ trypsin inhibitor $\mathrm{ml}^{-1}$ to stop the reactions and the protein patterns were analysed immediately by SDS-PAGE and Western blotting.

Immunofluorescence microscopy. Immunofluorescence microscopy was performed as described by Merck et al. (1997). Mouse mAbs directed either against the SFV B-cell epitope $(1: 500)$ (generously provided by C. Kraaijeveld, Utrecht University, The Netherlands) or against the periplasmic C-terminal tail of OmpA $(1: 100)$ (generously provided by $\mathrm{M}$. Kleerebezem, University Hospital, Utrecht, The Netherlands) were used as primary antibodies. Texas-red-conjugated goat anti-mouse antibody $(1: 100)$ (Southern Biotechnology Associates) was used as secondary antibody. Labelled cells were visualized in a Leica DM IBRE fluorescence microscope by both fluorescence and phase-contrast microscopy at $100 \times$ magnification.

In vivo porin activity assay. Porin activity was assessed by the $\beta$-lactamase assay, originally described by Zimmermann \& Rosselet (1977). In this assay, the diffusion of externally added $\beta$-lactam antibiotics through the outer membrane is the ratelimiting step in their degradation by periplasmic $\beta$-lactamase. The various mutant proteins were expressed in E. coli strain CE1224 carrying plasmid pBR322 to ensure a high expression of $\beta$-lactamase. The bacteria were grown overnight under phosphate-limiting conditions to induce expression of FomA from the phoE promoter. The bacterial cells were washed once with buffer A (10 mM HEPES, $5 \mathrm{mM} \mathrm{MgCl}_{2}, 0.9 \%$ $\mathrm{NaCl}, \mathrm{pH} 7$ ) and subsequently resuspended in buffer $\mathrm{A}$ to $\mathrm{OD}_{660}=1 \cdot 0$. The bacterial suspension was diluted 90 times in buffer A and aliquoted into five tubes, $0.9 \mathrm{ml}$ in each. Starch/iodine reagent was prepared by mixing $10 \mathrm{ml} 2 \mathrm{M}$ acetic acid, $4 \mathrm{ml} 1 \mathrm{M} \mathrm{NaWO}_{4}$ and $2 \mathrm{ml} 2 \%$ (w/v) starch solution (in $1 \mathrm{M}$ acetic acid) with $200 \mu \mathrm{l} 8 \mathrm{mM} \mathrm{I}_{2}, 320 \mathrm{mM} \mathrm{KI}$, and adjusting the volume to $20 \mathrm{ml}$ with water. The assay was performed in a $22^{\circ} \mathrm{C}$ water bath and the bacterial suspensions and starch/iodine reagent were preincubated for at least 10 min. The reaction was initiated by adding $100 \mu \mathrm{l} 8 \mathrm{mM}$ cephaloridine to the bacterial suspensions and was stopped after $0,5,10,15$ and $20 \mathrm{~min}$ by adding $1 \mathrm{ml}$ starch/iodine reagent. $A_{623}$ was measured exactly $20 \mathrm{~min}$ after the reaction was stopped and the rate of uptake was calculated $\left(\Delta A_{623}\right.$ $\left.\min ^{-1}\right)$. Supernatants of the cell suspensions were examined for $\beta$-lactamase activity, revealing that in all cases studied, leakage of $\beta$-lactamase was negligible.

\section{RESULTS}

\section{Construction of mutant fomA genes}

To examine the proposed topology model of FomA (Fig. 1a), linkers encoding an SFV epitope (Table 1) were inserted at various sites in the fom $A$ gene. This was done by introducing unique BamHI sites, followed by subsequent insertion of linkers encoding the foreign epitope as described in Methods. The constructs obtained are summarized in Table 2.

\section{Expression and folding of the mFomAs}

The mFomAs carrying the SFV epitope after aa 245 or small insertions after aa 167,215 or 333 were not expressed at levels detectable with anti-FomA antiserum on blots (results not shown). All other mFomAs were present in the cell envelopes at levels comparable to wtFomA (Fig. 2), with the exception of SFV-211 which was present at markedly lower levels (Fig. 2, 10-fold excess of cell envelopes loaded). FomA is heatmodifiable (Bakken et al., 1989b), a property shared with several other OMPs (Dekker et al., 1995; Heller, 1978) and explained by the faster migration of the compactly folded native proteins relative to the denatured proteins in SDS-PAGE. All $\mathrm{mFomAs}$ were also heat-modifiable (Fig. 2), indicating their proper folding. A proportion of SI-236 and SFV-236 was denatured at room temperature, indicating that this fraction was not correctly assembled in the membrane.

\section{Pore activity of the mFomAs}

The uptake rate of the $\beta$-lactam antibiotic cephaloridine was measured to assess the function of the mFomA porins. Functional porins will imply proper folding of the mFomAs and changes in uptake rates will reflect steric effects or changes in the distribution of charged amino acid residues (Van Gelder et al., 1997). Five independent assays were performed, where the same amount of bacterial cells expressing the various $\mathrm{mFomAs}$ was used. Exactly the same amount of bacterial cells as used in the $\beta$-lactamase assay was also applied to an SDS-polyacrylamide gel and the amounts of wtFomA and $\mathrm{mFomAs}$ were quantified as described in Methods. For each of the five assays, the protein quantification data were used to correct the uptake rates for the amount of FomA expressed. The mean of the wtFomA measurements was set to $100 \%$ and the $\mathrm{mFomA}$ measurements are given as a percentage of wtFomA (Table 2). E. coli strain CE1224 carrying only plasmid pBR322, and thus expressing no major porin, was used as a control for the background level of uptake and revealed that the level was less than $1 \%$ of the wtFomA activity. All mFomAs facilitated the uptake of cephaloridine, with the exception of SFV-211 which was expressed, probably, at a too low level. SFV-19, SFV105, SFV-116, SFV-191, SI-236 and SFV-287 had uptake rates comparable to wtFomA. This indicates that these proteins have insertions in parts of the protein that are non-critical for the pore activity, most likely in surfaceexposed regions. SFV-97, SFV-130, SFV-143 and SI-245 seemed to have somewhat reduced rates, whereas only SFV-138 and SFV-236 had drastically reduced uptake rates compared to the wild-type.

\section{Surface exposure of the inserted SFV epitope}

All mFomAs containing the inserted SFV epitope were recognized by an anti-SFV epitope $\mathrm{mAb}$ on a Western blot (not shown). To assess potential exposure of the epitope on the cell surface, indirect immunofluorescence labelling was performed. CE1224 cells expressing 


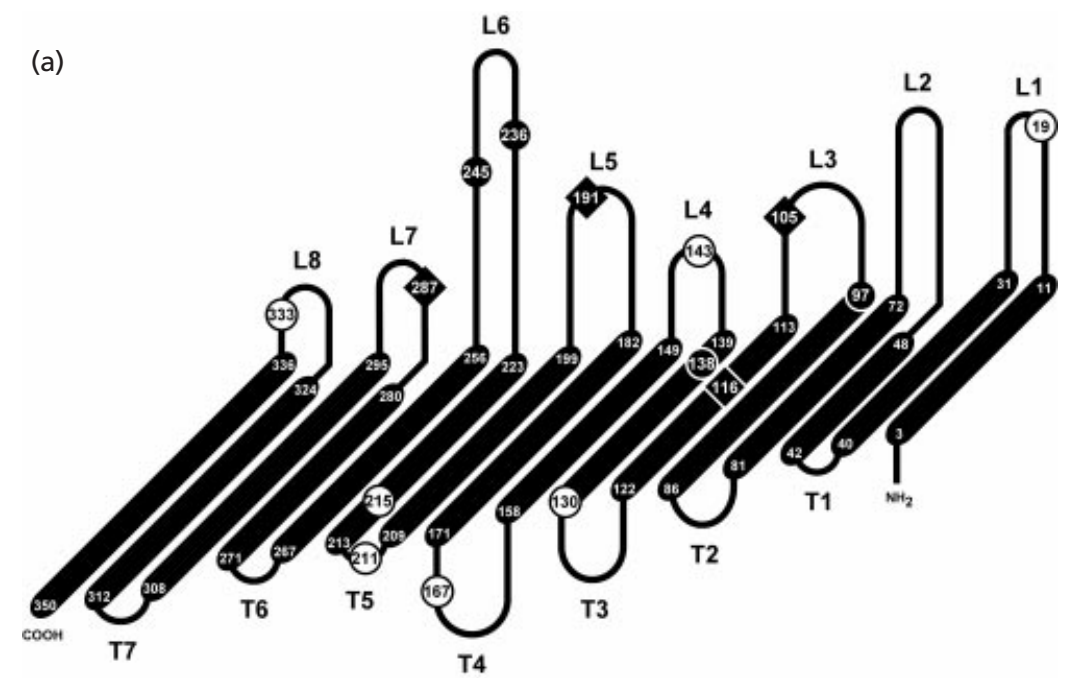

(b)

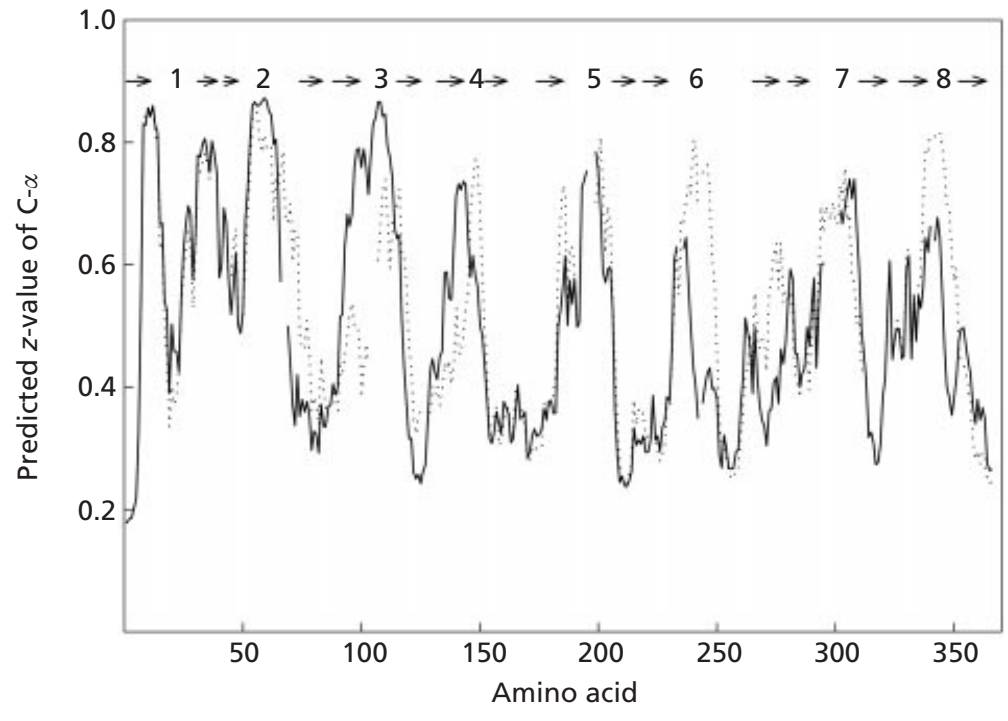

Fig. 1. (a) Diagram of the topology model of the FomA protein from $F$. nucleatum ATCC 10953. The top of the diagram shows the putative surface-exposed loops and the broad lines show the putative transmembrane segments. The codons of the last unchanged amino acids prior to the novel BamHI sites are marked with circles or diamonds. Some of the results obtained with the various insertion mutants are indicated. SFV epitope insertions made at sites marked with black diamonds were recognized by the anti-SFV epitope mAb on intact cells by immunofluorescence microscopy. Insertions made at sites marked with black diamonds or black circles lead to the exposure on the surface of novel trypsin sites. The numbering of aa 1-135 corresponds to the sequence published by Bolstad et al. (1994). V136 of the published sequence has later been shown not to be present (H. Kleivdal, unpublished results) and the numbering of aa 137-351 of the original sequence has been revised to 136-350. (b) Topology plot of the FomA protein of $F$. nucleatum ATCC 10953 (continuous line) and $F$. periodonticum ATCC 33693 (dotted line) as predicted by the neural network topology prediction method (Diederichs et al., 1998). To be able to directly compare the plots of the two FomA proteins, breaks in the lines corresponding to gaps in the alignment were introduced. A predicted $z$-value of 0.6 or less corresponds to a transmembrane or periplasmic location, whereas higher values correspond to extracellular loops. Arrows correspond to the $16 \beta$ strands of the FomA topology model and the numbers between the arrows correspond to the loops. The plots for the FomA proteins of the $F$. nucleatum strains ATCC 25586 and Fevl were highly similar to the ones shown.

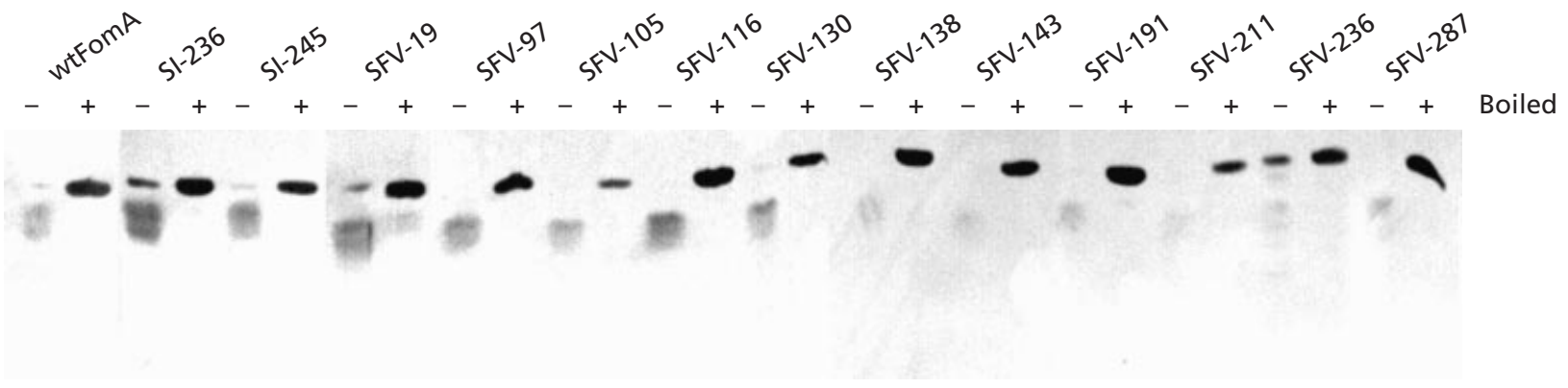

Fig. 2. Expression and heat modifiability of mutant FomA proteins carrying insertions. The analysis was performed by Western blotting with cell envelope samples of $E$. coli CE1224 cells expressing the mFomAs. Samples were either boiled for $5 \mathrm{~min}(+)$ or incubated at room temperature $(-)$ prior to SDS-PAGE as indicated. The antiserum $\phi 239$ directed against the FomA protein was used to detect the mFomAs on the immunoblots. The same amount of cell envelope was applied in all lanes except the SFV-211 lane, where 10 times the amount was used. 


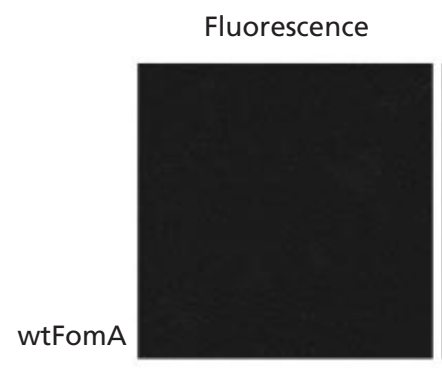

Phase contrast

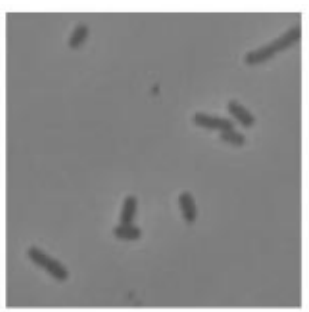

SFV-105
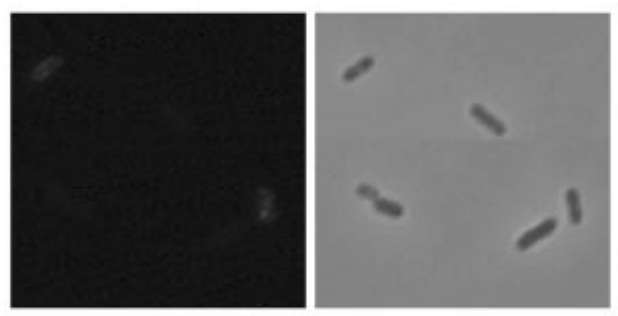

SFV-116

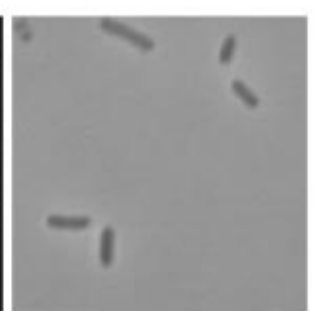

Fluorescence

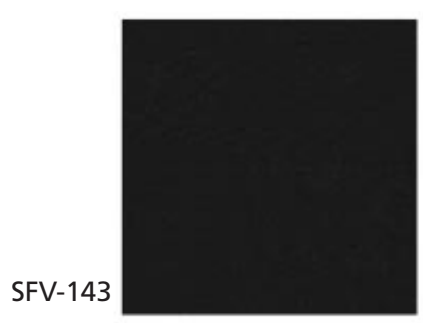

SFV-191

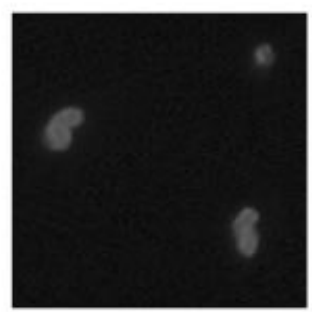

SFV-287

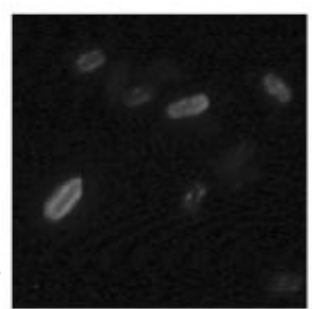

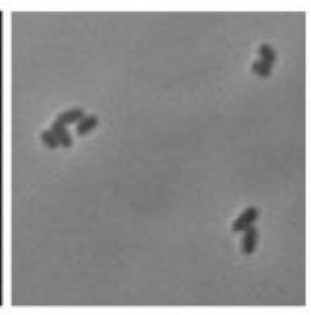

Phase contrast
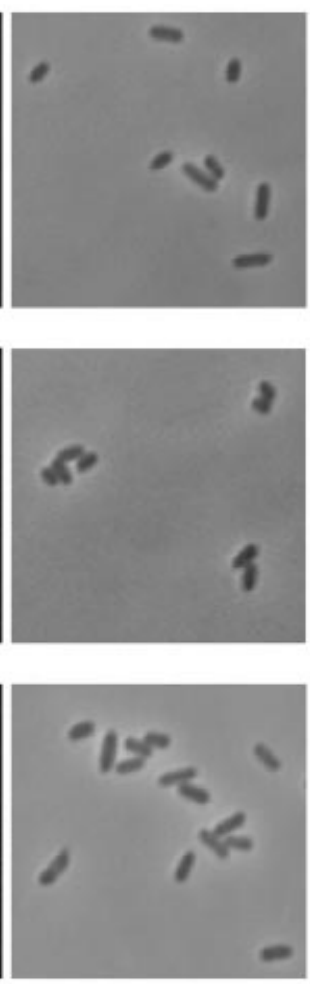

Fig. 3. Immunofluorescence microscopy of fixed E. coli CE1224 cells expressing mutant FomA protein carrying the SFV epitope at various insertion sites. Labelling was performed with an mAb directed against the SFV epitope. The cells were visualized by a Texas-red-conjugated secondary antibody and magnified $100 \times$.

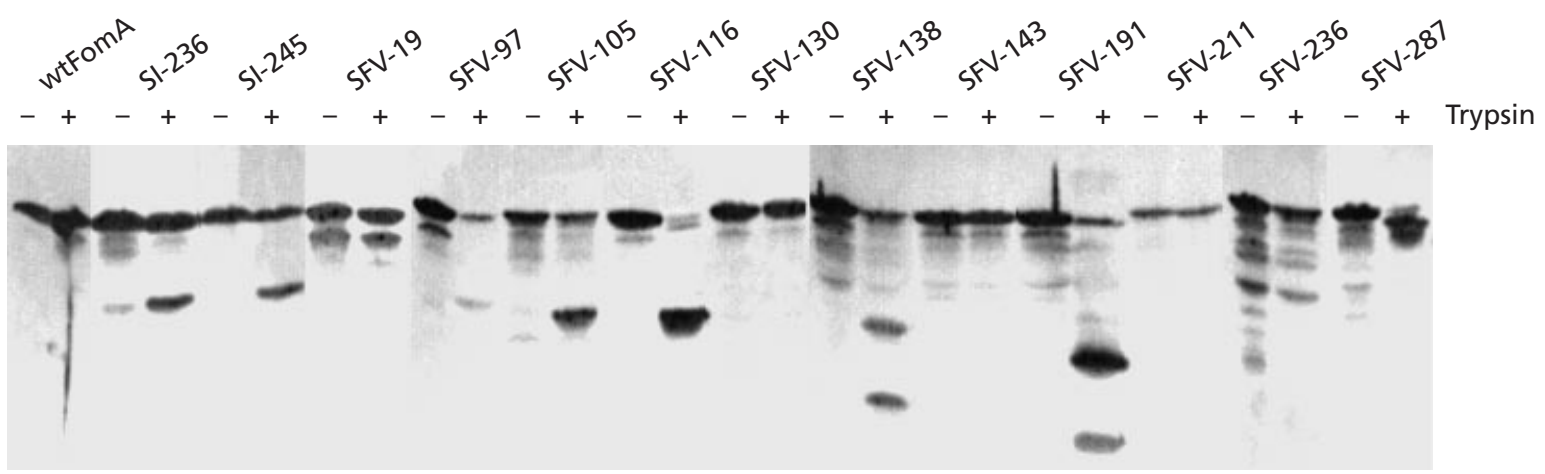

Fig. 4. Trypsin accessibility of the mutant FomA proteins in intact E. coli CE1224 cells expressing the various insertion mFomAs. The results from the trypsin treatment were revealed by the anti-FomA antiserum $\phi 239$ in Western blots. The same amount of whole cells was applied in all lanes except the SFV-211 lane, where 10 times the amount was used.

$w t$ FomA were used as a negative control. In addition, an $\mathrm{mAb}$ directed against the periplasmic C-terminal part of OmpA was used as a control for outer-membrane integrity. None of the cells harbouring mutated fom $A$ genes were labelled with the OmpA mAb (not shown), verifying that the cells assayed were intact. Four of the 11 SFV epitope mutant proteins were clearly recognized by the anti-SFV epitope mAb, namely SFV-105, SFV116, SFV-191 and SFV-287 (Fig. 3), demonstrating that the insertion sites 105, 116, 191 and 287 are in or near surface-exposed loops. All four proteins had rates of uptake of cephaloridine comparable to wtFomA, consistent with the notion that the proposed loops L3, L5 and L7 are indeed surface-exposed.

While immunofluorescence microscopy studies require that the entire epitope is exposed, only part of the insertion is required to expose a novel trypsin site 
(Merck et al., 1997). The FomA protein contains 20 Arg and 30 Lys residues distributed evenly in the entire primary structure, but is not processed when intact $E$. coli cells expressing FomA are treated with trypsin (Fig. 4). Whole cells were treated with trypsin in the presence of $\mathrm{Mg}^{2+}$ to assess exposure of trypsin-sensitive sites in intact cells. The OmpA protein remained intact after trypsin treatment (Tommassen \& Lugtenberg, 1984), demonstrating the integrity of the outer membrane (data not shown). The mFomAs carrying the SFV epitope after aa 97, 105, 116, 138, 191 and 287 were all partially or completely processed by trypsin (Fig. 4). In addition, mFomAs carrying a 6 aa insertion after aa 236 and 245 showed partial degradation (Fig. 4). The molecular masses of the trypsin-generated fragments were estimated from Western blots and are given in Table 2 together with the expected sizes (if trypsin cleaves at the middle of the insert). In general, the trypsin-generated fragments were estimated to be somewhat larger than the expected sizes, which is also the case for the fulllength $\mathrm{mFomA}$ proteins. The trypsin-generated fragments correspond either to the expected C-terminal fragment (SFV-97, SFV-105 and SFV-116), the expected N-terminal fragment (SI-236, SI-245 and SFV-287) or both (SFV-143 and SFV-191). The results confirm the surface exposure of loops L3, L5 and L7, and are also consistent with the proposed surface exposure of loops L4 and L6.

\section{DISCUSSION}

Epitope insertion mutagenesis was chosen as the approach to verify the topology model of FomA. Immunofluorescence microscopy studies on intact E. coli cells expressing the various $\mathrm{mFomAs}$ using an $\mathrm{mAb}$ against the inserted SFV epitope strongly support the surface exposure of loops L3, L5 and L7 (Fig. 3). Although the SFV epitope is long enough to span the membrane, it does not contain a long enough amphipathic stretch to fulfil the role as a transmembrane segment. Thus, it is highly unlikely that an insertion to a periplasmic site would lead to surface exposure of the epitope, giving false positives. The surface exposure of loops L3, L5 and L7 was confirmed by the trypsin accessibility experiments and the results obtained were also consistent with the surface exposure of loops L4 and L6 (Fig. 4, Table 2). Insertion mutants of FomA may become sensitive to trypsin either due to exposure of novel inserted trypsin sites (Table 2) or as a result of conformational changes leading to exposure of normally hidden sites. The $\mathrm{mFomAs}$ that have surface-accessible trypsin sites are all heat-modifiable and functional porins, strongly suggesting correct folding of the proteins and that longrange structural alterations are unlikely. The sizes of trypsin-generated fragments (Table 2) also correspond well with the expected sizes, indicating that the exposed trypsin sites are actually in or near the insertion.

According to the topology model, insertion sites 97, 105 and 116 are all postulated to be situated in or near loop L3. In the bacterial porins of which the structure has been resolved, including the PhoE protein of E. coli, loop
L3 is not exposed to the cell surface, but forms a constriction within the channel at half the height of the membrane (Cowan, 1993; Montal, 1996; Weiss et al., 1991). Insertion mutants carrying multiple copies of a 9 aa epitope inserted into the third loop of PhoE displayed results that were consistent with loop L3 being located within the pore channel, since at least three copies of the epitope were needed to expose one copy of the epitope to the surface (Struyvé et al., 1993). The fact that both SFV-105 and SFV-116 were recognized by the anti-SFV $\mathrm{mAb}$ on intact cells, together with the trypsin accessibility of SFV-97, strongly indicate that loop L3 of the FomA protein is surface-exposed. Although the permeability rate for cephaloridine seemed to be somewhat affected by the insertion made after aa 97, one would expect the permeability rates to be more strongly affected by such a large insertion if the third loop existed as a constriction loop (Struyvé et al., 1993). Thus, it seems highly unlikely that the third loop of FomA folds into the barrel in the same manner as the third loop of PhoE (Cowan et al., 1992).

Whereas the results suggest that site 116 is cell-surfaceexposed, this site was postulated to be within a membrane-spanning segment according to the topology model. The SFV epitope appears to be located entirely in the N-terminal part of the insert (Fernandez et al., 1998) and the C-terminal part could thus function as a spacer that pushes the epitope to the surface. In addition, the 4 aa $C$-terminal to the epitope appear to be able to sustain the amphipathic properties of the putative transmembrane segment. Hence, it is entirely possible that insertion site 116 is actually located in a transmembrane segment, whereas the inserted epitope is accessible at the cell surface. This phenomenon has been observed in an epitope insertion mutagenesis study on LamB of E. coli, where some sites predicted to be external were in fact situated in transmembrane segments, as revealed by the X-ray structure (Newton et al., 1996). The fact that the cephaloridine uptake rate of SFV-116 was at wild-type level strongly suggests that the pore activity remains unaffected by this insertion. This may be in line with the interpretation mentioned above, but could also imply that the model is inaccurate in this area.

It has been suggested that instead of the third loop, the longest loop according to the topology model, loop L6, might form the constriction in the FomA channel (Bolstad et al., 1994). The results (Fig. 4), however, suggest that loop L6 is at least partly exposed to the surface. The fact that the SFV epitope insertions at these sites seemed to be less well tolerated than the 6 aa insertions (Fig. 2, Table 2), however, suggests an important structural or functional role. A significant amount of SFV-236 is probably incorrectly assembled in the membrane (Fig. 2) and hence non-functional. It is thus not safe to conclude that the observed reduction in the uptake rate of cephaloridine is due to a narrowing in the pore.

The surface exposure of L1 could not be demonstrated by the linker insertion approach, but the fact that SFV- 
19 showed wild-type pore activity may indicate surface exposure, since the only other SFV epitope insertion mutants that displayed wild-type pore activity, namely SFV-105, SFV-116, SFV-191 and SFV-287 all had the SFV epitope exposed to the surface. The surface exposure of L1 is supported by the fact that E29 becomes the new N-terminal amino acid upon proteolytic digestion of intact cells of $F$. nucleatum (Bakken et al., $1989 \mathrm{~b}$ ), showing that at least part of the proposed loop L1 is indeed surface-exposed.

The SFV epitope insertion after aa 143 was not detectable on intact cells. However, the results obtained with SFV-138 demonstrate the surface exposure of the region in the proximity of aa 138 . The reduced uptake rate of cephaloridine for both mutants carrying insertions in the proposed loop L4 may indicate that L4 is situated more closely to the pore channel than, for instance, loops L5 and L7, and is thus in line with the fact that loop L4 is poorly surface-exposed.

The work presented here demonstrates the surface exposure of five of the postulated loops, namely loops L3 to L7. Although exposure of loop L1 could not be confirmed by SFV-19, Bakken et al. (1989b) have provided chemical evidence that this loop indeed is surface-exposed in F. nucleatum. Thus, loops L2 and L8 are the only loops for which there is no experimental evidence. Kleivdal et al. (1999) recently identified positively charged amino acids in the FomA protein that were found to be important to pore function, which supported the topology model, where these amino acids are predicted to be located in transmembrane segments 5 and 6 and contribute to a hydrophilic pore lumen. In addition, when the FomA protein sequences were subjected to the recently published neural network topology prediction method (Diederichs et al., 1998), a virtually identical topology model was predicted (Fig. $1 \mathrm{~b})$, in spite of the fact that the FomA proteins have no sequence similarity to the proteins used to train the neural network. In conclusion, the topology model seems to a great extent to be supported by the presented results, and unlike the other non-specific porins, the third loop of FomA does not seem to be internal.

\section{ACKNOWLEDGEMENTS}

This work was supported by the Norwegian Research Council. We thank M. Kleerebezem for giving us the OmpAspecific $\mathrm{mAb}$, C. Kraaijeveld for providing the anti-SFV epitope $\mathrm{mAb}$ and Anne Fjellbirkeland for critically reading the manuscript.

\section{REFERENCES}

Agterberg, M., Adriaanse, H. \& Tommassen, J. (1987). Use of outer membrane protein $\mathrm{PhoE}$ as a carrier for the transport of a foreign antigenic determinant to the cell surface of Escherichia coli K-12. Gene 59, 145-150.

Bakken, V., Aaro, S., Hofstad, T. \& Vasstrand, E. N. (1989a). Outer membrane proteins as major antigens of Fusobacterium nucleatum. FEMS Microbiol Immunol 1, 473-483.
Bakken, V., Aaro, S. \& Jensen, H. B. (1989b). Purification and partial characterization of a major outer-membrane protein of Fusobacterium nucleatum. J Gen Microbiol 135, 3253-3262.

Bolstad, A. I., Tommassen, J. \& Jensen, H. B. (1994). Sequence variability of the $40-\mathrm{kDa}$ outer membrane proteins of Fusobacterium nucleatum strains and a model for the topology of the proteins. Mol Gen Genet 244, 104-110.

Bolstad, A. I., Hogh, B. T. \& Jensen, H. B. (1995). Molecular characterization of a $40-\mathrm{kD}$ a outer membrane protein, FomA, of Fusobacterium periodonticum and comparison with Fusobacterium nucleatum. Oral Microbiol Immunol 10, 257-264.

Bolstad, A. l., Jensen, H. B. \& Bakken, V. (1996). Taxonomy, biology, and periodontal aspects of Fusobacterium nucleatum. Clin Microbiol Rev 9, 55-71.

Charbit, A., Boulain, J. C., Ryter, A. \& Hofnung, M. (1986). Probing the topology of a bacterial membrane protein by genetic insertion of a foreign epitope; expression at the cell surface. EMBO J 5, 3029-3037.

Cowan, S. W. (1993). Bacterial porins: lessons from three highresolution structures. Curr Opin Struct Biol 3, 501-507.

Cowan, S. W., Schirmer, T., Rummel, G., Steiert, M., Ghosh, R., Pauptit, R. A., Jansonius, J. N. \& Rosenbusch, J. P. (1992). Crystal structures explain functional properties of two E. coli porins. Nature 358, 727-733.

Dekker, N., Merck, K., Tommassen, J. \& Verheij, H. M. (1995). In vitro folding of Escherichia coli outer-membrane phospholipase A. Eur J Biochem 232, 214-219.

Diederichs, K., Freigang, J., Umhau, S., Zeth, K. \& Breed, J. (1998). Prediction by a neural network of outer membrane $\beta$-strand protein topology. Protein Sci 7, 2413-2420.

Fernandez, I. M., Harmsen, M., Benaissa-Trouw, B. J., Stuij, I., Puyk, W., Meloen, R. H., Snippe, H. \& Kraaijeveld, C. A. (1998). Epitope polarity and adjuvants influence the fine specificity of the humoral response against Semliki Forest virus specific peptide vaccines. Vaccine 16, 1531-1536.

Hanahan, D. (1983). Studies on transformation of Escherichia coli with plasmids. J Mol Biol 166, 557-580.

Heller, K. B. (1978). Apparent molecular weights of a heatmodifiable protein from the outer membrane of Escherichia coli in gels with different acrylamide concentrations. J Bacteriol 134, 1181-1183.

Ho, S. N., Hunt, H. D., Horton, R. M., Pullen, J. K. \& Pease, L. R. (1989). Site-directed mutagenesis by overlap extension using the polymerase chain reaction. Gene 77, 51-59.

Jensen, H. B., Skeidsvoll, J., Fjellbirkeland, A., Hogh, B., Puntervoll, P., Kleivdal, H. \& Tommassen, J. (1996). Cloning of the fomA gene, encoding the major outer membrane porin of Fusobacterium nucleatum ATCC10953. Microb Pathog 21, 331-342.

Kaufman, J. \& DiRienzo, J. M. (1989). Isolation of a corncob (coaggregation) receptor polypeptide from Fusobacterium nucleatum. Infect Immun 57, 331-337.

Kleivdal, H., Benz, R. \& Jensen, H. B. (1995). The Fusobacterium nucleatum major outer-membrane protein (FomA) forms trimeric, water-filled channels in lipid bilayer membranes. Eur J Biochem 233, 310-316.

Kleivdal, H., Benz, R., Tommassen, J. \& Jensen, H. B. (1999). Identification of positively charged residues of FomA porin of Fusobacterium nucleatum which are important for pore function. Eur J Biochem 260, 818-824. 
Kolenbrander, P. E. \& London, J. (1993). Adhere today, here tomorrow : oral bacterial adherence. J Bacteriol 175, 3247-3252.

Levinthal, C., Signer, E. R. \& Fetherolf, K. (1962). Reactivation and hybridization of reduced alkaline phosphatase. Proc Natl Acad Sci USA 48, 1230-1237.

Lugtenberg, B., Meijers, J., Peters, R., van der Hoek, P. \& van Alphen, L. (1975). Electrophoretic resolution of the 'major outer membrane protein' of Escherichia coli K12 into four bands. FEBS Lett 58, 254-258.

Merck, K. B., de Cock, H., Verheij, H. M. \& Tommassen, J. (1997). Topology of the outer membrane phospholipase A of Salmonella typhimurium. J Bacteriol 179, 3443-3450.

Moeck, G. S., Bazzaz, B. S., Gras, M. F., Ravi, T. S., Ratcliffe, M. J. \& Coulton, J. W. (1994). Genetic insertion and exposure of a reporter epitope in the ferrichrome-iron receptor of Escherichia coli K-12. J Bacteriol 176, 4250-4259.

Montal, M. (1996). Protein folds in channel structure. Curr Opin Struct Biol 6, 499-510.

Nakae, T. (1976). Identification of the outer membrane protein of E. coli that produces transmembrane channels in reconstituted vesicle membranes. Biochem Biophys Res Commun 71, 877-884.

Newton, S. M., Klebba, P. E., Michel, V., Hofnung, M. \& Charbit, A. (1996). Topology of the membrane protein LamB by epitope tagging and a comparison with the X-ray model. J Bacteriol 178, 3447-3456.

Ohmori, H. (1994). A new method for strand discrimination in sequence-directed mutagenesis. Nucleic Acids Res 22, 884-885.

Snijders, A., Benaissa Trouw, B. J., Oosterlaken, T. A. \& 7 other authors (1991). Identification of linear epitopes on Semliki Forest virus E2 membrane protein and their effectiveness as a synthetic peptide vaccine. J Gen Virol 72, 557-565.

Struyvé, M., Visser, J., Adriaanse, H., Benz, R. \& Tommassen, J. (1993). Topology of PhoE porin: the 'eyelet' region. Mol Microbiol 7, 131-140.
Sukhan, A. \& Hancock, R. E. (1995). Insertion mutagenesis of the Pseudomonas aeruginosa phosphate-specific porin OprP. J Bacteriol 177, 4914-4920.

Taylor, I. M., Harrison, J. L., Timmis, K. N. \& O'Connor, C. D. (1990). The TraT lipoprotein as a vehicle for the transport of foreign antigenic determinants to the cell surface of Escherichia coli K12: structure-function relationships in the TraT protein. Mol Microbiol 4, 1259-1268.

Tommassen, J. \& Lugtenberg, B. (1984). Amino terminus of outer membrane PhoE protein: localization by use of a bla-phoE hybrid gene. J Bacteriol 157, 327-329.

Tommassen, J., van Tol, H. \& Lugtenberg, B. (1983). The ultimate localization of an outer membrane protein of Escherichia coli $\mathrm{K}-12$ is not determined by the signal sequence. EMBO $\mathrm{J} 2$, 1275-1279.

Towbin, H., Staehelin, T. \& Gordon, J. (1979). Electrophoretic transfer of proteins from polyacrylamide gels to nitrocellulose sheets: procedure and some applications. Proc Natl Acad Sci USA 76, 4350-4354.

Van Gelder, P., Saint, N., Phale, P., Eppens, E. F., Prilipov, A., van Boxtel, R., Rosenbusch, J. P. \& Tommassen, J. (1997). Voltage sensing in the PhoE and OmpF outer membrane porins of Escherichia coli: role of charged residues. J Mol Biol 269, 468-472.

Weiss, M. S., Abele, U., Weckesser, J., Welte, W., Schiltz, E. \& Schulz, G. E. (1991). Molecular architecture and electrostatic properties of a bacterial porin. Science 254, 1627-1630.

Welte, W., Nestel, U., Wacker, T. \& Diederichs, K. (1995). Structure and function of the porin channel. Kidney Int 48, 930-940.

Zimmermann, W. \& Rosselet, A. (1977). Function of the outer membrane of Escherichia coli as a permeability barrier to betalactam antibiotics. Antimicrob Agents Chemother 12, 368-372.

Received 17 November 1999; revised 1 February 2000; accepted 27 February 2000. 